Biological Sciences | Felix Dapare Dakora \& Glory Chinonye Mbah

\title{
Legumes can help to eliminate trace element deficiency in Africa
}

Nutrient-poor soils in Africa is a pressing issue. As a result, many people in the African continent suffer from nutrient deficiency due to not being able to access nutritious foods. This is what makes the work of Professo Felix D. Dakora of Tshwane Univerity of Technology so research into finding foods thet research ins finding foods that consumption in the diet, and $h$ work demonstrating that the application of nitrates, typically found in fertilisers, can actually decrease the amount of trace elements in certain foods, is of vital importance for.

Uutrient deficiency is a major health problem on a global scale, and nowhere is this issue the inherently low concentration of nutrients in African soils, exacerbated by the common practice of cultivating crops without fertilisers, and the remova of left-over crop residues after grain problem in the continent.

This is where the work of Professor Felix Dakora and his Research Group at the Tshwane University of Technology comes into play. Professor Felix Dakor is at the forefront of researching solutions that ensure people receive enough trace elements in their diets. Funded by the Bill and Melinda Gates Foundation, the National Research Foundation of South Africa, the South African Research Chair in Agrochemurgy and Plant Symbioses, and the Tshwan

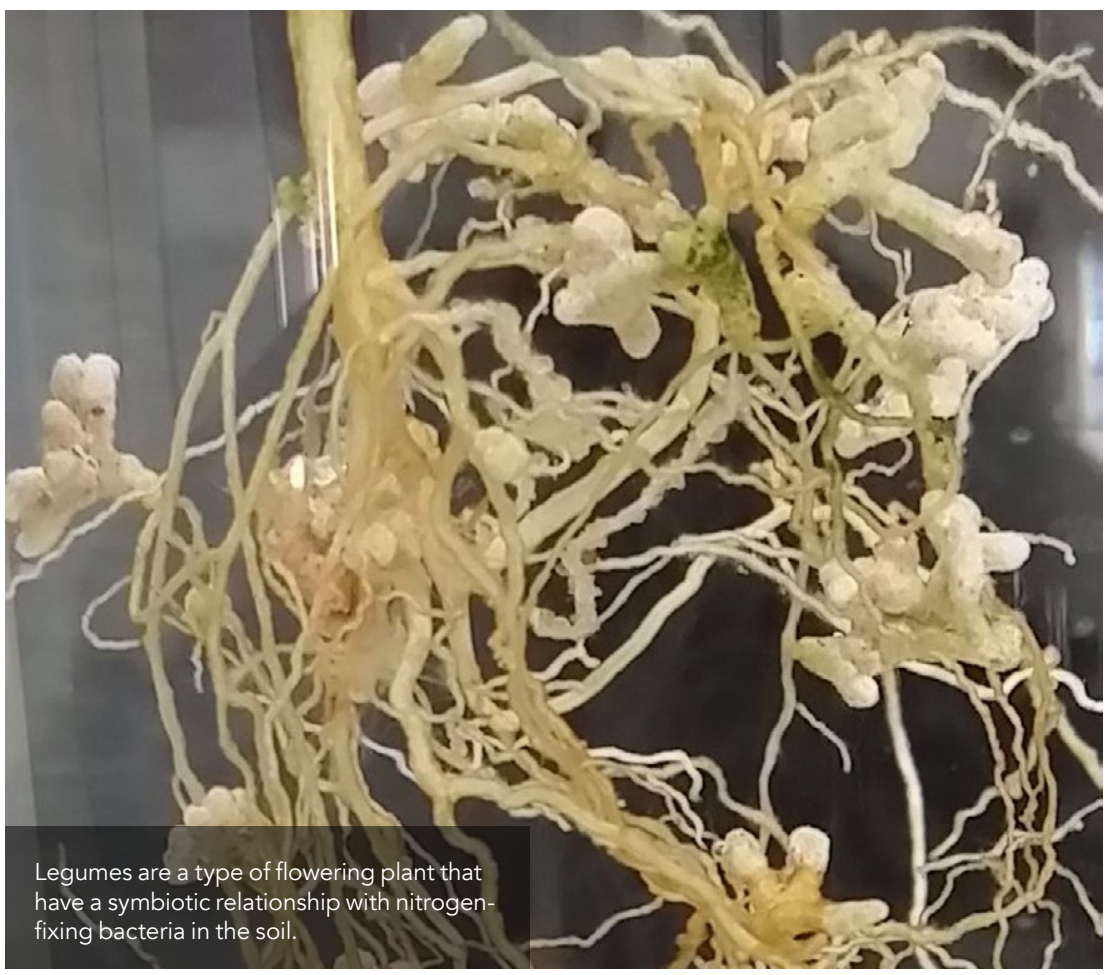

University of Technology, Pretoria, Professor Felix Dakora is well placed duct this research.

\section{A BACKGROUND TO THE PROBLEM} Due to the inherently low levels of nutrients in African soils, approximately 232 million people suffer from trace element deficiency in the African

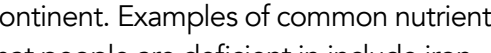
zinc, selenium and iodine. Trace elements are chemical elements present only in minute amounts in soil and have a relatively low presence in foods. Despite being found in low levels, these trace elements are nonetheless important.

In small doses, they are vital for brain development and are purported to reduce the risk of chronic diseases such as cancer, cardiovascular disorders and age-related degenerative diseases. Their deficiency can also lead to stunted growth, a critical issue when considering that many children suffer from trace in Africa.

In South Africa, the problem is so plementing food materias for child with trace elements such as iron zinc and selenium in order to meet the dietary requirements recommended by the World Health Organization. While this is of course a necessary short-term solution, it is not sustainable in the long-term.

Although eating seafood, dairy products and meat can provide trace element supplements to the diet, this is not a feasible solution for poorer communities in rural Africa, as these communities

\section{THE POTENTIAL OF LEGUMES} Due to not being able to rely on anima products for nutrition, Professor Felix

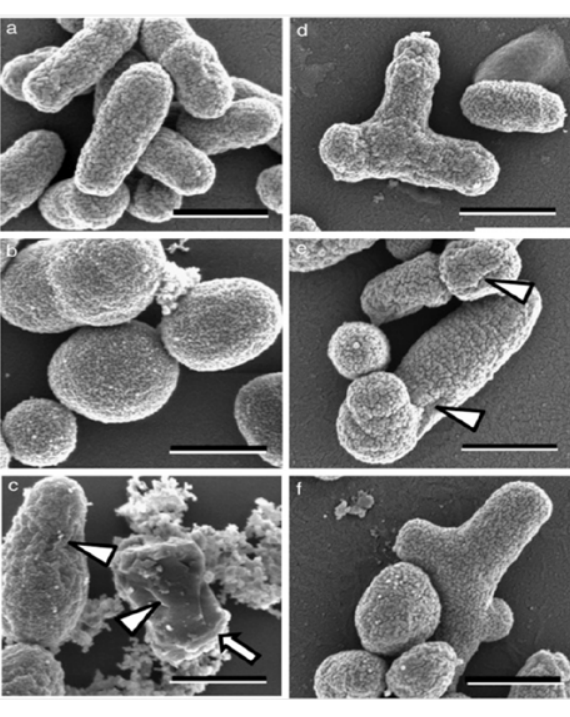

Biological Nitrogen Fixation (BNF): a green agricultural technology. $\mathbf{N}_{2}$ ase $\mathrm{N}_{2}+8 \mathrm{e}=8 \mathrm{H}^{+}+16 \mathrm{ATP} \longrightarrow 2 \mathrm{NH}_{3}+\mathrm{H}_{2}+16 \mathrm{ADP}+16 \mathrm{Pi}$

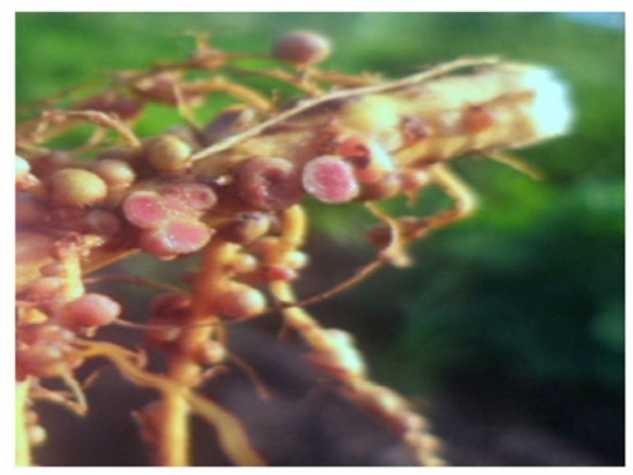

Uses light energy from the sun via photosynthesis

Low carbon footprint
Soil bacteria known as Rhizobia form root
on legumes and fix nitrogen from the air.

in which to increase trace elements in peoples' diets through increasing the consumption of certain types specifically been researching the potential for legumes to be used as a way of increasing the amount of trace elements that people have access to in their diets.

Legumes are already known for their ability to provide plant protein, but there has been little assessment of the relationship between legumes and mineral accumulation prior to Professor

A legume is a type

of flowering plant that has a symbiotic relationship with nitrogen-fixing bacteria in the soil.

This means that the bacteria live in the root systems of the plant and convert nitrogen gas from air in the soil into ammonia, which is then used by both the bacteria and the plant to grow. The bacteria benefit from being able to live in the plant roots where they obtain food made by the plant for their growth, while the plant in turn benefits from nitrogen compounds produced by the bacteria. As a result, legumes are able to take up more mineral nutrients from the soll, thus increasing the amoun
Due to the low levels of nutrients in soils, approximately 232 million people suffer from trace element deficiency in Africa.

the potential of cowpea consumption for preventing trace element deficiency within children; this has huge implications for human nutrition and health.

To further this research, Professor Felix Dakora and his Group also studied the concentrations of trace elements in the different genotypes of cowpea. Genotypes are types of the same species but wi slightly different genetic makeups,

This research has incredible practical implications. For example, if certain genotypes of cowpea have higher of theirleaf oftrace mis to be consess in order to obtain a satisfactory amount of trace elements in the diet. This means that growing certain types of cowpea health benefits.

Professor Felix Dakora's work also indicates that the cowpea genotypes that contain higher amounts of trace nitrogen fixers, due to their physiological make up. This means that they are efficient at the process previously mentioned; and they are able to accumulate large amounts of nitrogen

Understanding this is crucial; with careful breeding of select plants, the high nitrogen-fixing trait could be enhanced. This research has the potential to overcome trace element deficiency in rural Africa through plant breeding.

Significantly, this research shows that the consumption of legumes has grea potential to decrease trace element did nony in humans. While the study did not necessarily indicate how these consumed Profill be processed when paved the way for fur Fix Dakora has paved the way for further research, in particular to identify suitable plants that edible plant parts. 


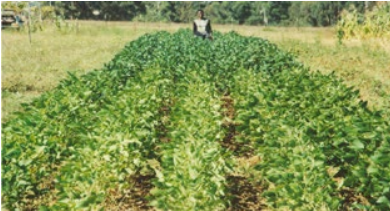

\section{Soybean

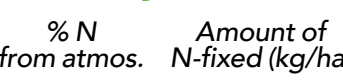 $50-97 \quad 23-220$}

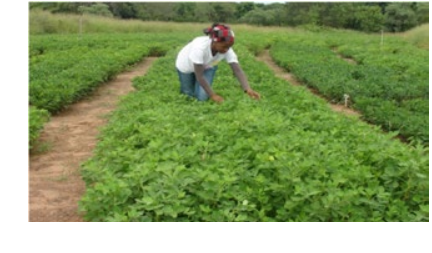

Mung Bean Amount of
$\% \mathrm{~N}$ 66-86 $31-111$
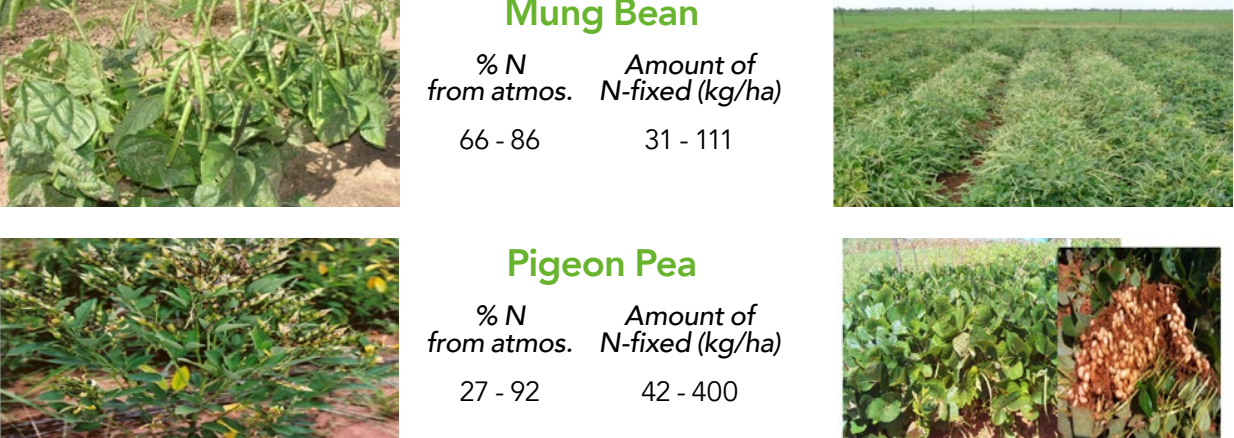

Pigeon Pea $\begin{array}{cc}\% N & \begin{array}{c}\text { Amount of } \\ \text { from atmos. }\end{array} \\ N \text {-fixed (kg/ha) }\end{array}$ $27-92 \quad 42-400$

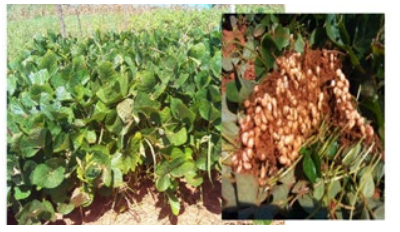

Kersting's Groundnut $\begin{array}{cc}\% \mathrm{~N} & \begin{array}{c}\text { Amount of } \\ \mathrm{N} \text {-fixed ( } \mathrm{kg} / \mathrm{ha})\end{array} \\ \text { from atmos. } & 23 \mathrm{~m}-12\end{array}$ $40-75 \quad 23 m-102$

\section{THE PROBLEM WITH NITRATES} Professor Felix Dakora has done additional research into the issue of trace element deficiency, but taking a different path, which looks at the potential of adding nitrates to plants to increase
the amounts of minerals and nutrients that they contain. Nitrate fertilisers are notorious for contributing both to ground and water pollution, as well as to global warming. Despite this, they are thought of as the solution to increasing crop yields, and therefore food security in many situations. However, in a study undertaken in 2012, along with studen researchers in his laboratory, Professor case Dakora demonstrated that in the in Africa, adding nitrates to crops would have the opposite intended effect.

The study tested how several legume plants (including cowpea) would respond to the addition of nitrates. The results of his study showed that adding nitrates to five different legume species
significantly altered the concentration of significantly altered the concentration of

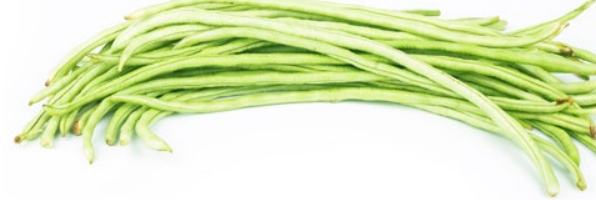

Nitrate fertilisers can significantly decrease the concentration of trace elements, thus
the dietary value of legume leaves.
Professor Dakora has paved the way for further research, showing that more needs to be done to identify suitable

crop plants that exhibit high levels of trace elements.

mineral elements in their leaves, stems and roots. In many of the legumes, for example, in one species, commonly known as water blossom pea (Podalyria calyptrata), the concentrations of calcium increased in all parts of the plant, while

These increases in nutrients can be explained; as the plant feeds on nitrates it alsone ats toke in potassium and While this may sound like good news, the study actually found that while nitrates can increase concentrations of some elements, nitrate supply significantly decreases the concentration of trace elements, thus decreasing the dietary value of legume leaves. The study tions zinc and boron species after nitrates $h$ ad in four legume The study also found tha been applied. of nitrates to legumes as they grow had the potential to decrease the ability of these plants to fix nitrogen, which is so desperately needed for sustainable crop growth and yields. Professor Felix Dakora's research has shown that certain types of plants can contribute more teficency and that athoce elent deficiency and that although nitrate use can increase some nutrients in plants, it cannot be used to solve the probetor Taken together this research provides a very clear takeaway message; that there certain ways to decrease trace element deficiency in rural Africa.

Although trace element deficiency is a serious problem in many rural areas in Africa, Professor Felix Dakora's research into both the potential of legumes to contribute to lowering rates of trace element deficiency and the effects of adding nitrates to these plants is of is necurity in Africa, and nutriona is not in Afica, and th nitrate use crucial importance. He has shown that including legumes in agricultural system certain nutrient quantities increased; is huge potential for legumes grown in

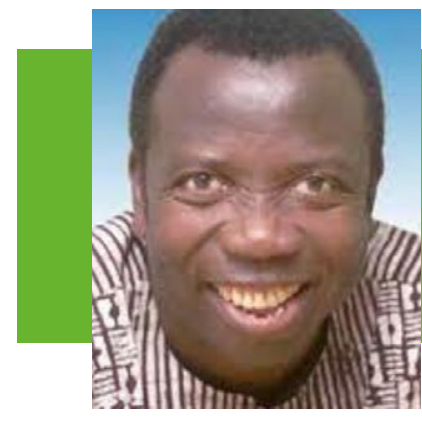

\section{Behind the Research}

\section{Professor Felix Dapare Dakora}

\section{Research Objectives}

Professor Dakora's research investigates biological nitrogen fixation with a focus on the legume, the interaction between

\section{Detail}

\section{Bio}

Prof Dakora completed his PhD degree in Botany in 1989 at the University of Western Australia, and is currently Plant

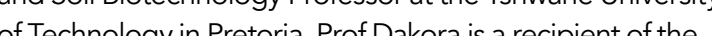
UNESCO-Equatorial Guinea International Prize for Research in the Life Sciences; the African Union Kwame Nkrumah Science Excellence Award and is a Fellow of the Academy of Science of South Africa, Fellow of the African Academy of Sciences, as well as Fellow of The World Academy of Sciences for the developing countries (TWAS). In 2017, Prof Dakora was elected President of the African Academy of Sciences.

\section{Funding}

The Bill and Melinda Gates Foundation, the National Research Foundation of South Africa, the South African Research Chair in Agrochemurgy and Plant Symbioses, and the Tshwane University of Technology, Pretoria.

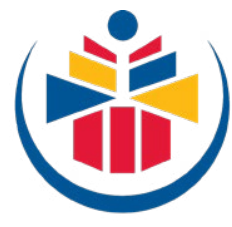

Tshwane University of Technology We empower people

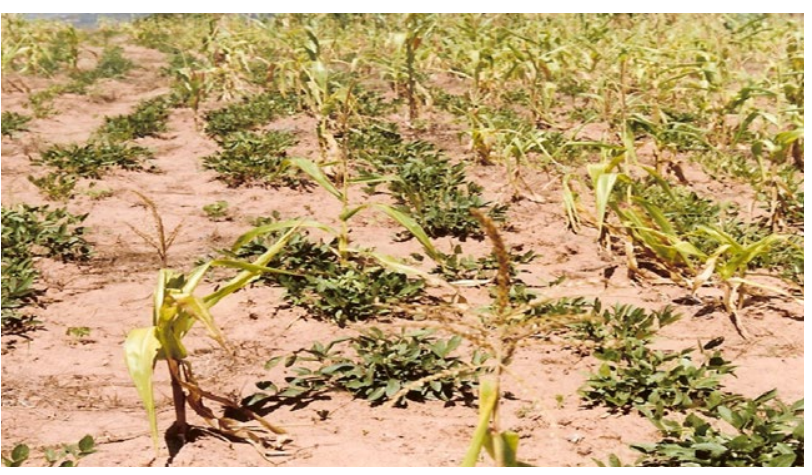

hoto shows a yellowish maize crop growing on an African soil that is poor in nutrients, while the associated Bambara groundnut crop (a legume) is
References

Dakora, F.D., Belane, A.K. (2019). Evaluation of protein and L. Walp.) leaves and seeds. Front. Sustain. Food Syst. 3:70 https://doi.org/10.3389/fsufs.2019.00070

Samson B.M. Chimphango, Charles F. Musil \& Felix D. symbiotic and nitrate-fed nodulated legumes exposed to elevated UV-B radiation. Journal of Plant Nutrition, 35:1, 1-20. http://dx.doi.org/10.1080/01904167.2012.631663 Belane, A.K., Dakora, F.D. (2011). Levels of nutritionallyleaves and grain of 27 nodulated cowpea (Vigna unguiculat L. Walp.) genotypes grown in the Upper West Region of Ghana. Food Chemistry. 125(1):99-105. DOI: 10.1016/j. foodchem.2010.08.044

Belane, A.K., Makhubedu, I.T., Pule-Meulenberg, F., Dakora, accumulation of mineral nutrients by cowpea (Vigna unguiculata L. Walp.) Crop and Pasture Science. 65(3):250. DOl: $10.1071 / \mathrm{CP} 13283$

\section{Personal Response}

\section{What further research needs to be done on trace}

作 trace element uptake by cereal crops is our next research the concentrations of trace elements in nitrogen-fixing
legumes, this me tration current practice of supplementing maize with trace elements in South Africa can be found by identifying absorption of these trace elements by maize and increased cereal crops. That way, the greater concentrations of trace elements in cereal grain will help to eliminate trace element deficiency in Africa. More research also needs to be done to identify many different food plants that show high levels of to understand how these trace elements are the human body when consumed in food. Furthermore, we need a better understanding of how trace elements are reduced when nitrate is supplied to the plant. My ultimate aim is to completely eliminate trace element deficiency in
rural Africa using food plants that have the ability to take up
more trace elements from soils. 